\title{
The Effect of Explicit Reading Strategy Instruction on Reading Comprehension of Upper Primary Grade Students
}

\author{
Dawit Tibebu Tiruneh ${ }^{1, *}$ \\ ${ }^{1}$ Centre for Instructional Psychology and Technology, Katholieke Universiteit Leuven, 3000 \\ Leuven, Belgium \\ *Correspondence: Centre for Instructional Psychology and Technology, Katholieke \\ Universiteit Leuven, 3000 Leuven, Belgium. Tel: 32-1632-6284. E-mail: \\ dawittibebu.tiruneh@ppw.kuleuven.be
}

Received: July 17, 2014

Accepted: August 7, 2014 Published: August 25, 2014

doi:10.5296/ije.v6i3.5989

URL: http://dx.doi.org/10.5296/ije.v6i3.5989

\begin{abstract}
This article describes a quasi-experimental study that adopted a pre-test-post-test design with a control group to examine the effect of an explicit reading strategy instruction on students' reading comprehension. Two intact eighth grade classes were randomly assigned into an experimental $(n=33)$ and a control $(n=32)$ condition. The experimental class was explicitly taught to use REAP reading strategy for 10 lessons, and students' reading comprehension progress during each lesson was evaluated. The control class was taught using the regular method of teaching reading for 10 lessons, and their reading comprehension progress in each lesson was assessed using open-ended item worksheets. The reading comprehension performance of the two groups was measured both before and after the experiment (separate pretest and posttests). Analyses of the pretest-posttest reading comprehension scores revealed that the experimental class significantly outperformed the control class. Analyses of students' reading comprehension progress in each of the lessons also indicated that those in the experimental condition demonstrated consistent improvement in their reading comprehension scores than those in the control condition. The findings suggest that explicit reading strategy instruction is effective in enhancing reading comprehension of upper primary grade students with limited prior experience of utilizing reading strategies.
\end{abstract}

Keywords: reading comprehension, REAP, reading strategy, primary school 


\section{Introduction}

Reading comprehension is a foundation to students' overall academic success in school (Alvermann \& Earle, 2003; Guthrie, 2004; OECD, 2009; Zywica \& Gomez, 2008), and a prerequisite for successful participation in most areas of adult life (Cunningham \& Stanovich, 1997; Smith, Mikulecky, Kibby \& Dreher, 2000). It is emphasized that without the skills of reading comprehension and the motivation for reading to learn, students' academic progress is limited (Alvermann \& Earle, 2003). Recognizing such benefits of reading, learning to read has become one of the most crucial learning processes students are involved in at primary school (Pressley, 1998). However, becoming a proficient reader is not that easy for everyone. Especially with regard to the ultimate goal of reading comprehension, many school children appear to have huge and persistent problems.

Accordingly, reading strategy instruction has become one of the most crucial learning processes students are involved in primary school (Pressley, 1998). Research shows that instruction in reading strategies contribute significantly in enhancing students' reading comprehension (Duke \& Pearson, 2002; Guthrie, 2004). Mastery and use of effective reading strategies is considered as essential for an increased text comprehension (Palincsar \& Brown, 1984; Pressley, 1998; Williams, 2005). However, evidence shows that reading comprehension strategies are not taught in schools as often as it should be. For instance, Duke and Pearson (2002) reported that very little comprehension instruction occurs in many classrooms, especially in primary grades, and comprehension instruction that does occur is often incomplete and ineffective. Aarnoutse and Leeuwe (1995) also revealed that the practice of teaching reading in classrooms is very traditional where teachers mostly fail to adequately explain and model effective reading strategies in the classrooms. A comprehensive study conducted in primary schools of least income countries such Ethiopia also revealed that students are not taught to employ relevant reading strategies during reading lessons (USAID, 2010).

The purpose of the present study is to examine the effect of an explicit reading strategy instruction in developing the reading comprehension of upper primary school students in Ethiopia. Attempts are made to identify characteristics of an effective reading strategy instruction that could improve reading comprehension of primary school students with limited previous experiences in utilizing reading strategies.

\subsection{Research on reading strategy instruction}

Previous research shows that explicit reading strategies instruction, with a great deal of supervised student practice and feedback from the teacher, is a feasible way to help students improve their reading comprehension (De Corte, Verschaffel, \& De Ven, 2001; Pressley, 2000). A number of findings (e.g., De Corte, et al., 2001; Eanet \& Manzo, 1976; Palincsar \& Brown, 1984; Simpson \& Nist, 1990) pointed out that students who were trained to use reading strategies scored better in their reading comprehension than those who were not trained. It appears that the main difference between effective and weak readers is their ability to use reading strategies and to know which particular strategies are valuable. 
There are two waves of research on reading strategies instruction. The first wave includes those individual strategies which proved their worth in improving the reading comprehension of students. Among the few are prior knowledge activation (Anderson \& Pearson, 1984), summarization (Duke \& Pearson, 2002), and questioning (Rosenshine, Meister \& Chapman, 1996). Various studies validated those individual comprehension strategies as effective in stimulating students' understanding of reading texts. In their analyses of various individual reading strategies, Pressley \& Wharton-McDonald (1997) explained why such strategies increase comprehension of texts. It is justified that those strategies worked because they encouraged the development of text representations that children do not develop in the absence of reading strategy instruction.

The second wave of research includes those involving multiple strategies in authentic and meaningful classroom settings. This wave of research focused less on identifying new effective strategies and more on the most effective ways to teach students to use the individual strategies together (e.g., Pressley \& Wharton-McDonald, 1997). The emphasis here is more of categorizing individual strategies that, when taught together, leads to improved comprehension.

Reciprocal teaching (RT) is among the most known multiple strategy instructions (Palincsar \& Brown, 1984). RT involved teaching students to use four comprehension strategies: predicting, questioning, seeking clarification, and summarizing. Palincsar \& Brown (1984) explicitly trained their students to employ RT in reading texts, and found out that RT significantly improved the reading comprehension of students. Subsequent studies (e.g., Rosenshine \& Meister, 1994) also proved that RT is an effective reading strategy instruction.

Transactional strategies instruction is the other multiple strategy instruction, which involves teaching students to apply a repertoire of strategic processes (Pressley et al., 1992). It is a framework designed to improve comprehension through the use of explicit strategy instruction, student practice with teacher feedback, and scaffolding about where and when to use the strategies. Instruction is transactional among group members, between the reader and text, and through socially constructed meaning.

REAP is the other comprehensive multiple strategy instruction that encompasses many of the important individual strategy instructions (Eanet \& Manzo, 1976). REAP is an acronym for the following stages of reading: Read, Encode, Annotate and Ponder. This reading strategy is noted as useful in helping students actively interact with the text and construct meaning while reading. Eanet and Manzo asserted that the use of REAP through modeling and guided practice supports increased comprehension and also develop students' higher-order thinking and writing skills (Eanet \& Manzo, 1976).

The following is a description of each of the stages involved in REAP (Eanet \& Manzo, 1976):

$\mathbf{R}$ - Read through the text quickly and predict the writer's main idea.

$\mathbf{E}$-Encode the text by putting the main ideas in your own words/language. Use the text margin to write key words and notes, underline and highlight key words from the text. 
A - Annotate the text by writing a statement that summarizes the important points and share it with others. Tell the student next to you in more detail what the text is about, let him/her tell you and discuss the differences.

P - Ponder/ process what you read by thinking and talking with others. Reflect on the meaning and seek connections with what you know to increase memory.

Eanet and Manzo noted that at the heart of the REAP strategy is teaching students how to annotate or summarize a text. They pointed out that writing annotations force students to attend to various aspects of text which typically would be overlooked and the reader is required to discriminate and synthesize the ideas presented by the writer, translate these into his/her own language, and crystallize the result in writing (Eanet \& Manzo, 1976). Generally, REAP is based on premises that: (a) a text becomes more meaningful when readers communicate its information to themselves or others, (b) students read with added attention when they are to write about it afterwards, so the once passive reading becomes more active, and (c) students tend to process information more deeply and has more meaning when they write about it afterwards (Eanet \& Manzo, 1976). It is assumed that in the course of revisiting the text for each of the stages of REAP, students internalize the content of the reading as they think about ways to represent the main ideas and message in the author's and their own words. When students move to the Ponder stage, they must connect with the text at a higher level through analysis and synthesis of the information in the text. The four REAP episodes are consecutive. Each of the stages contributes to the reading comprehension of students and highest comprehension could be possible when readers carry out all the activities involved in each stage.

\subsection{The present study}

Although there are significant achievements in access and equity of primary education in Ethiopia, quality of primary education has been a critical concern (USAID, 2010). Evidence gathered in three national learning assessments (NOE, 2000; NOE, 2004; MoE, 2008), and a comprehensive study conducted by the USAID on early grade reading (USAID, 2010) has proved the claim that quality of primary education is at stake.

The Ministry of Education in Ethiopia claims that early grade reading achievement is an indication for quality of the early part of the school system (USAID, 2010). Accordingly, the quality of early grade reading has been assessed at different periods recently. Three national learning assessments at the first and second cycles of primary education were carried out. In 2000, the baseline national learning assessment (BNLA) was undertaken (NOE, 2000). In 2004 the second national learning assessment (SNLA: NOE, 2004), and in 2008 the third national learning assessment (TNLA: MoE, 2008) was conducted. The main objective of the national learning assessments was to determine what primary school students achieved upon completion of first cycle (Grade 4) and second cycle (Grade 8) in light of the minimum learning competencies set by the Ministry of Education.

The result in the 2008 TNLA indicated that students' reading comprehension achievement decreased (mean $=43.9$ ) compared with either the 2004 SNLA (mean=64.5) or the 2000 
BNLA (mean=64.3). Particularly, the 2008 TNLA break down of scores by subject indicated that nearly $51.7 \%$ of the students scored below "basic" on reading comprehension. In order to determine the areas of reading in which children have particular difficulty, an Early Grade Reading Assessment (EGRA) was undertaken nationally in 2010 in grades 1 through 4. The findings of EGRA indicated that while children attend school for two or three years, a significant percentage of them were illiterate. When it comes specifically to reading comprehension, the finding showed that scores were extremely low, with more than $50 \%$ of the children in most regions of the country unable to answer a simple comprehension question (USAID, 2010).

The author's informal observation on the practice of reading instruction in few primary schools in Ethiopia also proves that students are not adequately taught to employ strategies during reading lessons. The current practice of teaching reading in primary schools is 'traditional', where the lessons typically involve teacher-led whole-class activities: asking comprehension questions after students read aloud a text, teacher evaluation of students' answers, and teacher presentation of the correct answers afterwards. Explicit and repeated instruction focusing on reading strategies is hardly practiced. Teachers do not explicitly teach relevant reading strategies and their usefulness for text comprehension, and do not model to the students when and how to apply effective reading strategies. There seems to be an assumption by teachers that once children acquire the basic ability to decode, they would automatically and without any specific instruction be able to understand whatever they could read.

In general, there is a concern that the existing reading instruction approach in primary schools in Ethiopia is not helping students to improve their reading comprehension (USAID, 2010). Referring to primary school students' current status of reading skills, it is recommended in the USAID study that systematic interventions targeting reading instruction and the provision of reading materials are essential (USAID, 2010). It is mainly suggested that reading strategy training for teachers on how to appropriately and successfully teach reading strategies to children is necessary.

The main purpose of this study was to design a reading instructional intervention targeting an upper primary school in Ethiopia, and examine its effect on students' reading comprehension. The main research question is: what is the effect of an explicit reading strategy instruction on the reading comprehension of upper primary grade students?

In order to design the reading lessons, the REAP reading strategy framework was selected. The REAP is found to be a comprehensive strategy instruction that is well-structured and easily applicable in contexts where both teachers and students have limited previous experiences in employing reading strategies. 


\section{Method}

\subsection{Research design and participants}

Quasi-experimental pre- and post-test design was employed. The study participants were grade 8 students in a public primary school in Ethiopia. Among a total of 6 grade $8^{\text {th }}$ classes during the academic year of 2011/2012, two classes were randomly selected. There was resource constraint to involve more than two classes. The two classes selected had one English language teacher ('Reading' is not given as a separate course in primary schools in Ethiopia, but integrated in the 'English as a Foreign Language' course). One of the classes was randomly assigned to the experimental condition ( $n=33 ; 16$ boys and 17 girls), and the other to the control condition ( $n=32 ; 14$ boys and 18 girls). The age of students in both conditions ranged from 13 to 16, with an average of 14 years and 2 months by the time of the experiment (May, 2012).

\subsection{Instrument}

\subsubsection{Reading comprehension tests}

Standardized tests that could measure reading comprehension of primary school students in Ethiopia were not available during the time of data collection. Hence, distinct tests that could be administered as pre-test and post-test were constructed by the researcher. Efforts were made to produce both valid and reliable tests. The format of the tests was familiar to the students and clear instructions on how to answer the items were given. Emphasis was given to make sure that the vocabulary level and the grammatical complexity of the items were appropriate to grade 8 students. The texts used to prepare the pre-test and post-test items had also similar level of difficulty in terms of vocabulary and text structure with that of the grade 8 reading textbook. Two regular reading teachers from the same school were requested to evaluate the clarity and difficulty level of the tests in the pre-and post-test. Some modifications were made on a few of the items based on feedbacks from the regular teachers.

The pre-test included 20 multiple-choice items, developed from a selected reading text. The post-test included 17 multiple choice and 3 open-ended items from a different text. In the post-test, 3 open-ended items were deliberately included to enhance slightly the difficulty level of the test. A sample of multiple-choice item used in the pre-test and an open-ended item used in the post-test is indicated in Figure 1. Cronbach's alpha coefficient was computed to measure the internal consistency of the pre-test and post-test. Alpha coefficient values above 0.7 are considered acceptable, and values above 0.8 are considered to reflect good test reliability (Cohen, Manion, \& Morrison, 2007). The internal consistency reliability of the pre-test was 0.74 and the post-test was 0.77 . The values fall within the acceptable range of reliability. 
A sample multiple-choice item used in the pre-test based on two separate reading texts:

Which of the following statements is true according to the passage?

A. All soccer players on the field are allowed touching the ball with their hands during a game.

B. There are totally 11 players in both teams during a soccer game.

C. The World Cup is organized every four years.

D. The World Cup competition started in 2006.

A sample open-ended item used in the post-test:

Why do you think discovering a medicine for Bilharzia was important enough to offer Dr. Aklilu a reward?

Figure 1. Sample multiple-choice and open-ended pre-post-test items

Ten reading texts were selected from grade 8 English language textbook with minor modification on the contents (a few words were added in some of the texts so that all the reading texts would have similar number of words: between $300 \& 350$ ). Each of the 10 texts were accompanied by a worksheet with the REAP structure and questions. The questions were based on the REAP stages: Read the text quickly; Encode the text in your own language; Annotate the text by writing down the message conveyed; and Ponder the message on your own and with the student next to you. Figure 2 shows a sample REAP worksheet based on a text titled "Ethiopian National Museum" (see Appendix 1 to read the reading text). The 10 reading texts were used during the practical REAP training for the regular teacher and also during the intervention for both the control and experimental conditions.

\subsubsection{Informal observation}

Informal observations were conducted on both the experimental and control classes during the 10 lessons, which were spread over 4 weeks. Notes were taken about the nature of students' involvement in both conditions, the time taken for the students to complete the reading activities in each lesson, and the teacher's activities during the lessons in both conditions. The informal observation data were used to supplement the data collected through the pre-post tests and the worksheets.

\subsection{Procedures}

\subsubsection{Teacher training}

The REAP strategy intervention was planned to be implemented by the regular classroom 
teacher. In such cases, introducing the reading strategy to the teachers and encouraging them to practice prior to the intervention is strongly suggested (Guthrie, 2004; Van Keer, 2004). Accordingly, 10 hours practical REAP strategy training was given for the regular teacher assigned to teach the selected classes. The training was given by the author of this study. Practical instruction on the hows, whys and whats of the REAP reading strategy across different reading texts was given to the teacher. The training was aimed to insure that the REAP could be implemented effectively during the actual lessons by the classroom teacher.

\begin{tabular}{|c|c|}
\hline $\begin{array}{l}\text { 1. Read } \\
\text { Read the text and think of a different title } \\
\text { for the text (use a few words). }\end{array}$ & $\begin{array}{l}\text { 2. Encode } \\
\text { 1. Put the main ideas in your own words in } \\
\text { two sentences. } \\
\text { 2. Which keywords in the text did not you } \\
\text { understand? Use your dictionary or ask } \\
\text { your teacher to explain! }\end{array}$ \\
\hline & \\
\hline $\begin{array}{l}\text { 3. Annotate } \\
\text { a) Write in two sentences a summary of } \\
\text { this text. } \\
\text { b) Compare the notes you have made so } \\
\text { far with the student next to you. }\end{array}$ & $\begin{array}{l}\text { 4. Ponder } \\
\text { a. What new things did you learn from the text? } \\
\text { Write it below and also explain to the student next } \\
\text { to you. } \\
\text { b . Have you ever visited the national museum? If } \\
\text { 'Yes', what was most interesting for you? If 'No', } \\
\text { which section of the museum would be most } \\
\text { interesting for you to visit and why? }\end{array}$ \\
\hline
\end{tabular}

Figure 2. Sample REAP worksheet for a text titled 'The National Museum'

The same reading texts were used during the intervention for students in the control condition. However, in this case, the texts were accompanied by worksheets with open questions. See Figure 3 for a sample of the worksheet with open questions.

Read the text and answer the following questions:

1. Why is the Ethiopian National Museum the leading museum institutions in Sub-Sahara Africa?

2. When was the National Museum founded, and where is it located?

3. When and where was Lucy founded?

4. Describe briefly what is available on each floor at the National Museum.

5. For how many days per week is the National Museum open for visitors?

Figure 3. Sample worksheet based on a text titled 'The National Museum' for the control class 


\subsubsection{Scoring procedures}

The scoring involved two sets of measures: the REAP worksheets and students' pre-post-test performances.

The implementation of REAP was analyzed from the worksheets the students filled in for each text. Students' responses to the four REAP episodes were scored in three scales: (2) answered correctly, (1) partially correct, and (0) not correct/not filled in. The mean score of students on each REAP lesson was calculated and plotted in a line graph. This enabled to see how adequately students practiced REAP during the whole lessons and determine the extent to which the use of REAP strategy has improved students' reading comprehension as the lesson progressed. In the same way, control condition students' answers to the open questions on each worksheet were scored using the same scale: (2) answered correctly, (1) partially correct, and (0) not correct/not filled in. The average score of students in each lesson was calculated and plotted in a line graph. The data helped to determine if the conventional reading instruction has brought improvement in students’ reading comprehension.

The questions both in the REAP and traditional worksheets were open items and primarily scored by the author. However, in order to ensure the worksheets are scored objectively, the regular teacher was requested to score a sample of the worksheets. Sample of 15 students were selected randomly from each of the conditions and their responses to the worksheets on each of the lessons were scored. The inter-rater agreement (correlation coefficients) for each of the worksheets in the control condition ranged from 0.74 to 0.89 . For the REAP worksheet scores, the inter-rater agreement (correlation coefficients) ranged from 0.73 to 0.86 . These values reveal consistency between the two raters' scores.

\section{Results}

The results of the study are presented in two sections. In the first section, a brief description is given about the implementation of the study related to the REAP training for the teacher, the REAP strategy instruction for the experimental class and the conventional reading instruction for the control class. In the second section, reading comprehension achievement of the two conditions on the pre- and post-tests, and comprehension scores in each 10 lessons during the intervention are presented. A qualitative description of teacher and student activities during the 10 lessons is also presented in the second section.

\subsection{Implementation}

\subsubsection{Implementation of the REAP teacher training}

Prior to teacher training, the author got permission from the school director and the classroom teacher to observe two regular reading lessons by the regular teacher. It was observed that the teacher hardly employed explicit reading strategy instruction during the reading lessons. In both lessons, the teacher started by introducing the title of the text to the whole class and selected few students to read aloud each of the paragraphs in turn. The teacher then requested the students to follow him attentively and started reading the text aloud for the whole class. 
Students were immediately asked to answer the comprehension questions that followed the text. The teacher read the open-ended textbook comprehension questions and asked a few willing students to give answers. If the answer was wrong, either the teacher gave the chance for another student to try or gave the correct answer himself. In both lessons, the teacher was focusing on assessing students' comprehension instead of teaching students how to comprehend the text. It was also observed that students hardly employed a systematic strategy aimed at both comprehending the text and responding to the comprehension questions.

The REAP teacher training then started after revealing both teacher and student activities during actual reading lessons. Although one teacher was required to involve in teaching the reading lessons for the two conditions, additional grade 8 Reading teacher was included during the REAP strategy training. This helped the training to be collaborative.

During the first day of the training ( 2 hours), REAP was introduced to the teachers as one of the effective reading strategies in enhancing students' reading comprehension. Teachers were introduced with the rationale and stages involved in REAP. The four episodes in REAP were explained and one page summary of the stages was given to teachers. One of the texts (see Appendix A) was selected during the first day and each of the REAP stages were modeled through thinking aloud by the author. The teachers were explained the thought processes used in arriving at the major ideas, when and how to mark key words on texts, and the writing and re-writing involved to compose a concise summary annotation. Overall, during the first day, the stage for the forthcoming practical REAP training was set.

During the next four consecutive trainings (2 hours/session), the teachers continued practicing the REAP strategy using the selected texts and completed the questions on the worksheet. Each day, teachers were encouraged to apply REAP strategy and discuss each other especially during the Annotate and Ponder stages. For example, after writing a summary/annotation of each text, they were required to exchange their annotations and evaluate what each of them annotated. Teachers were then provided a model annotation at the end of each lesson to help them compare what they have annotated in their worksheet. In the Ponder stage, teachers were encouraged to process what they have read, relate what they read with their background knowledge and respond to all the questions in the Ponder stage. In addition, teachers were instructed in all the lessons how they could apply the REAP strategy in their daily reading lessons.

\subsubsection{Implementation of the experimental sessions}

The REAP strategy instruction for the experimental class was conducted in 10 lessons, each 45 minutes duration. The lessons were spread over four weeks. Prior to the REAP training, a pre-test was administered. Initially there were 37 students who took the pre-test and started the REAP training. However, 3 students missed more than $40 \%$ of the lessons and 1 student did not take the post-test.

During the 10 lessons, it was observed that the 45 minutes was not adequate for the majority of the students to complete the REAP worksheet. Especially during the first 4 lessons, 
students spent very long time in reading the text and could not finish answering the four REAP questions in the allocated time. The majority of the students were found to have a poor reading background and applying the REAP strategy during the 10 lessons was not automatic. It was apparent that students require extensive practical training on the strategy to apply it effectively during reading lessons.

For the control condition, the reading materials and time allocated were the same as the experimental condition. However, the control group was taught through the regular method of reading in the school (as described in section 3.1.1). The students were required to answer open-ended questions after reading a text. Initially, there were 35 students who took the pre-test and participated in the reading lessons. However, 1 student missed $50 \%$ of the lessons and had no complete data. Two students also did not take the post-test. During the 10 lessons, it was observed that the control class students were also poor readers. However, compared to the experimental class, the large majority of students were able to complete the worksheet in the 45 minutes lesson.

\subsubsection{Reading comprehension achievement}

The mean scores of students' on the pre-test and post-test is shown in Table 1. ANCOVA was conducted to determine the effectiveness of REAP strategy instruction over the conventional instruction in improving students' reading comprehension. Two naturally constituted groups were assigned in the experimental and control condition. For this reason, preliminary check was conducted to ensure that the two conditions do not differ on the pre-test. ANOVA was therefore conducted with the two conditions (control and experimental) as independent variable, and the pre-test score as dependent variable. The result showed that there was no significant difference between the two groups on the pre-test: $\mathrm{F}_{(1,63)}=.21, P=.05$.

Table 1. Pre-test and post-test mean scores of the two conditions

\begin{tabular}{lllll}
\hline Condition & pre-test & \multicolumn{3}{l}{ post-test } \\
\cline { 2 - 5 } & Mean & SD & Mean & SD \\
\cline { 2 - 5 } Control $(\mathrm{N}=32)$ & 9.28 & 1.75 & $10.23^{*}$ & 1.76 \\
Experimental $(\mathrm{N}=33)$ & 9.52 & 2.11 & $12.77^{*}$ & 2.39 \\
Total $(\mathrm{N}=65)$ & 9.40 & 1.93 & 11.52 & 2.45 \\
\hline
\end{tabular}

* The mean difference between the post-tests on the two conditions is significant, $P=.05$.

After ensuring that there was no significant difference in the pre-test on the two groups, ANCOVA was conducted. The independent variable was the type of intervention (REAP, conventional method) and the dependent variable was the post-test scores of the two conditions. The pre-test scores were used as a covariate in the analysis. As shown in Table 1, the post-test mean score for the control condition is 10.23 and that of the experimental condition is 12.77. The ANCOVA test showed that there is a significant difference on the post-test score between the two conditions, favoring the students who received the REAP strategy instruction: $\mathrm{F}_{(1,63)}=31.8, P=.05$.

In order to gain a clear insight into the general reading comprehension progress during the 


\section{Macrothink}

International Journal of Education

ISSN 1948-5476

2014, Vol. 6, No. 3

lessons, students' comprehension in each lesson was measured using the open-ended worksheet items for the control class and the REAP worksheet items for the experimental class.

\subsubsection{Students' score on the open-ended items worksheet (control condition)}

For each reading lessons, reading texts with an open item worksheet was prepared and students were required to answer those questions in each lesson. The teacher conducted the lessons in the conventional method: requested selected students to read aloud each paragraph of the text, then read the text again by themselves (or sometimes the teacher himself read aloud the text), asked the students to answer comprehension questions and finally gave the correct answer. In each lesson, the teacher handed a text accompanied by the worksheet with open questions. Students were encouraged to write their answers to the open questions on the worksheet. The teacher moved around and provided individual supports when needed. The teacher collects the worksheets just before the end of each lesson (with students' name written on it), and gave feedback just before the beginning of the next lesson.

Each of the students' worksheets was scored to examine whether there was evidence of progress on students' reading achievement from the first to the last lesson during the intervention. The mean scores of students for the open-ended comprehension questions in each lesson are indicated in figure 4.

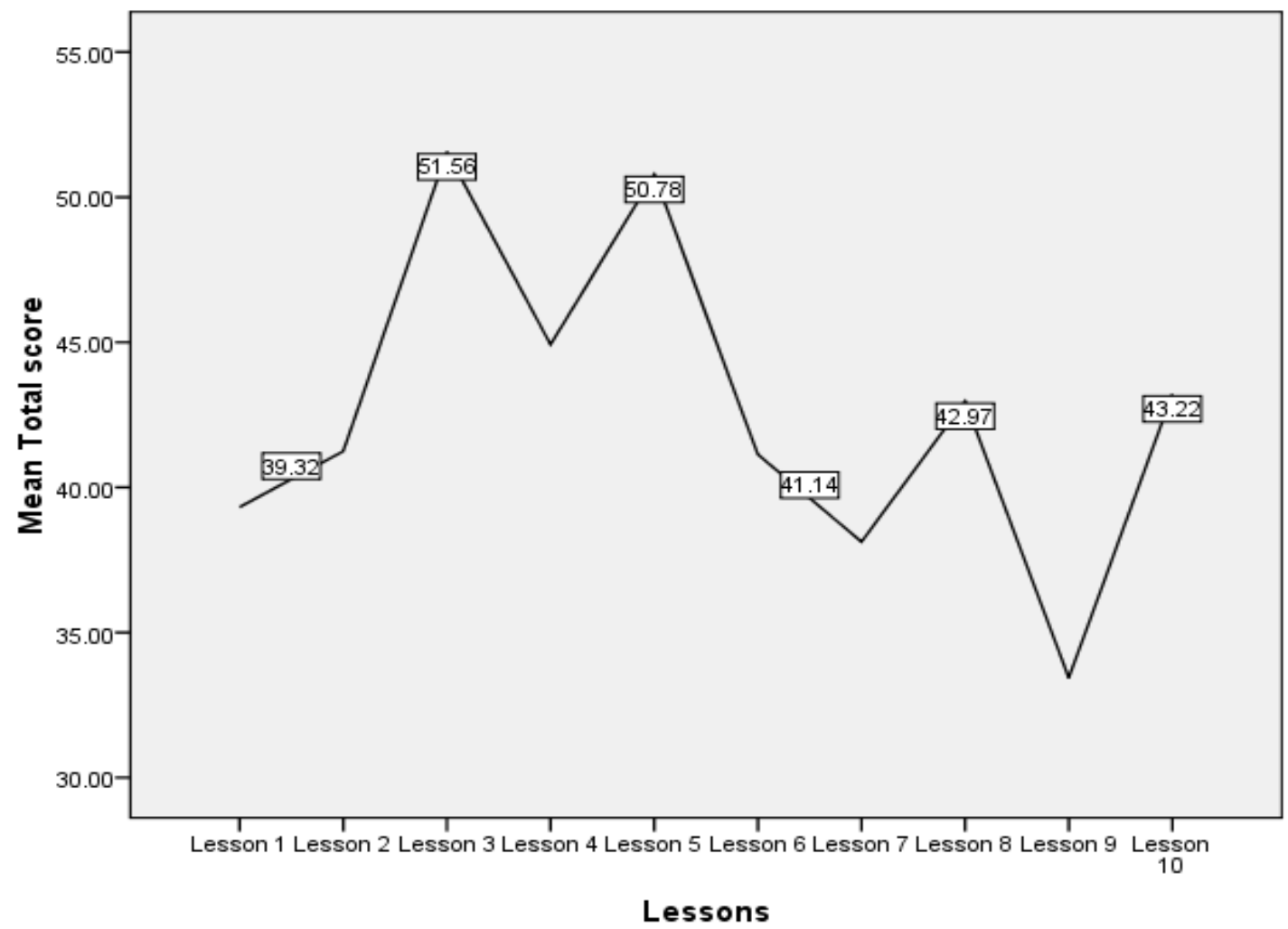

Figure 4. Line graph of the mean scores for the open item worksheets

As shown in Figure 4, students' reading comprehension score across the 10 lessons did not 
show a consistent progress. Until the first 3 lessons, students exhibited progress in their comprehension score, however that progress did not continue in the next lessons. Students' average score for lesson 3 (mean=51.6) was better than their scores for lesson 1 (mean=39.3) and lesson 2 (mean=41.3). However, students' average score during lesson 4 decreased (mean= 45.0). It is possible to observe from the line graph that students' learning progress is hard to predict. This implies students did not benefit from the conventional reading instruction and did not demonstrate consistent improvement in their reading comprehension.

According to the observations during the lessons, there was a very limited interaction with the teacher and among students during the lessons. Most of the time, students read the texts only for one round and started answering the comprehension questions on the worksheet. Most of the students read the texts arms crossed and were not observed in activities like underlining and highlighting key words, writing notes on the text margin, and summarizing what they have read.

\subsubsection{Students' score on the REAP worksheet (Experimental condition)}

In the experimental condition, the reading materials presented and time allocated were the same as the control condition, but the students were taught to apply REAP strategy. On the first day, the teacher introduced the REAP reading strategy. The classroom teacher explained to the students the rationale for applying REAP as a strategy and situations where REAP could be applied. Each of the REAP stages were explained to the students and a one page summary of the stages was given to each of the students. One sample text was chosen and the teacher continued his explanation by modeling each of the REAP stages through thinking aloud. Important information on how and when to use the strategy were modeled by the teacher. The teacher externalized as much as possible the strategic processes that usually occur internally and imparted procedural knowledge of the strategy. For instance, information such as which of the words in the text are key words; when and how do we mark important words/phrases; how could we identify the topic sentence; how could we write a concise summary of a paragraph; and how could we relate the information we read with our background knowledge; were presented through think-aloud statements.

The students were required to sit in pairs and given the first text with the REAP worksheet attached. The teacher guided and assisted the students in their use of the strategy. The teacher moved around and provided individual supports when needed. After completing the 'Annotate' task on the worksheet, students were requested to exchange their worksheets with the student next to each other, and compared their summaries. In the 'Ponder' stage, students were asked questions that could help them process the information they read and relate the information with their background knowledge. They were also required to communicate the ideas of the text to the student beside them. The teacher encouraged students to answer all the questions in the worksheet. At the end of the lesson, the teacher collects the worksheets (students' name was written on each worksheet), and gave a model annotation/summary of the text to help students compare with what they summarized. During the 10 lessons, the teacher and students continued the reading instruction more or less in a similar way, as mentioned above. 


\section{Macrothink}

In order to examine if students had showed progress in their reading comprehension during the whole REAP lessons, their answers to the REAP worksheets were analyzed. Students' responses to the four REAP episodes on the worksheet were scored in three scales: (2) filled in correctly, (1) partially correct, and (0) not correct/not filled in. As shown in Figure 5, students' scores during the 10 lessons have shown consistent improvement. It was revealed that students' reading comprehension has consistently improved during the whole lessons from mean of 1.67 in lesson 1 to mean 5.7 in lesson 10. This consistent performance indicated that the students were benefiting from the REAP strategy.

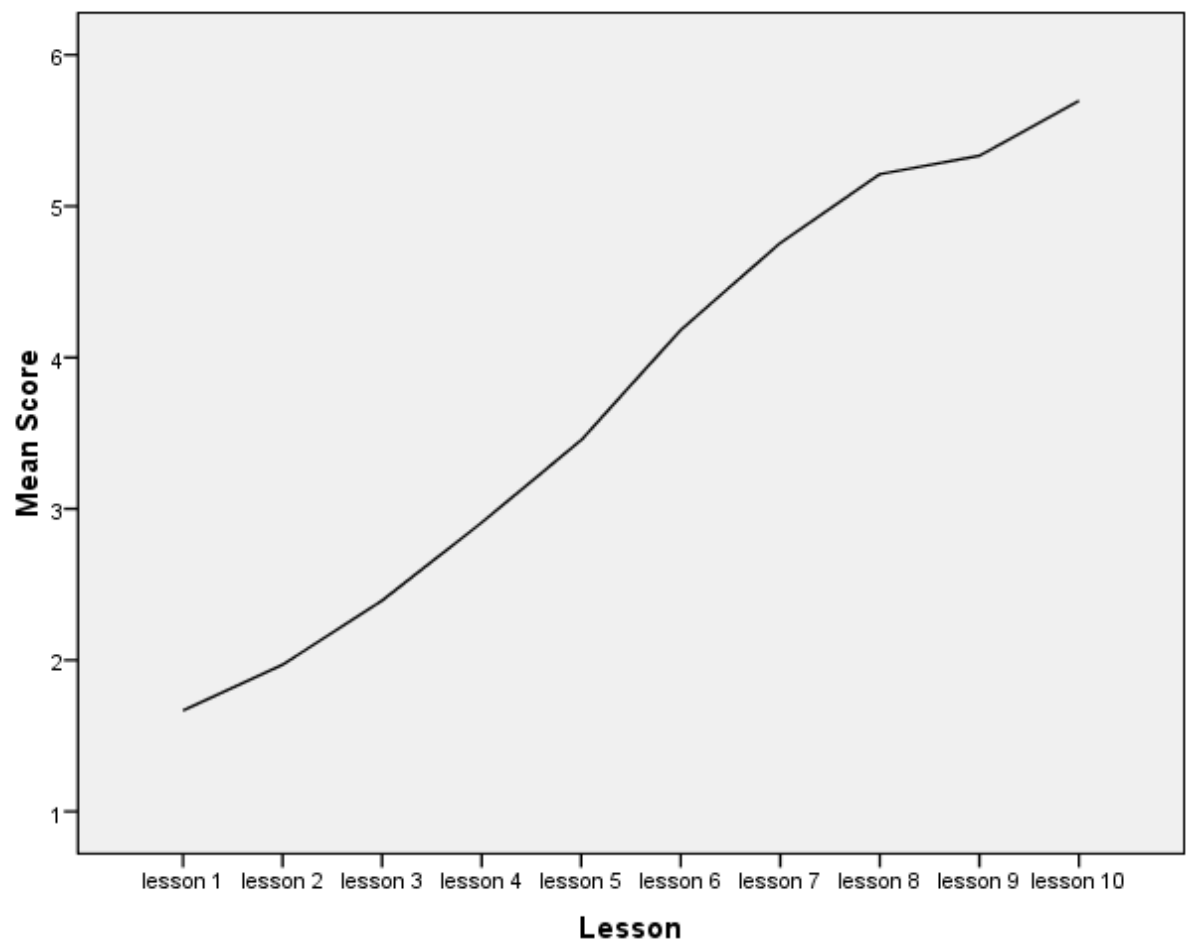

Figure 5. Line graph for the mean result on the REAP worksheet

Moreover, a closer look at the students' score on each of the REAP episodes (Read, Encode, Annotate, and Ponder) in the ten lessons revealed that their performance showed improvement. However, as indicated in Figure 6, students were not equally performing in all the REAP episodes. It is noted that students' performance on the 'Annotate' and 'Ponder' stage was relatively lower than their performance in the 'Read' and 'Encode' stage. Such difference on the four REAP episodes is expected because compared to the Read and Encode episodes, the Annotate and Ponder required higher level analysis of the text and it was not easy for students in the experimental group to develop such higher order thinking skills within 10 lessons. In addition, these students were novice to reading strategy instruction. However, the result still showed that students demonstrated gradual progress in all the REAP episodes (see Appendix 2 for a full list of students' mean scores during each lesson). 


\section{Average REAP scores}

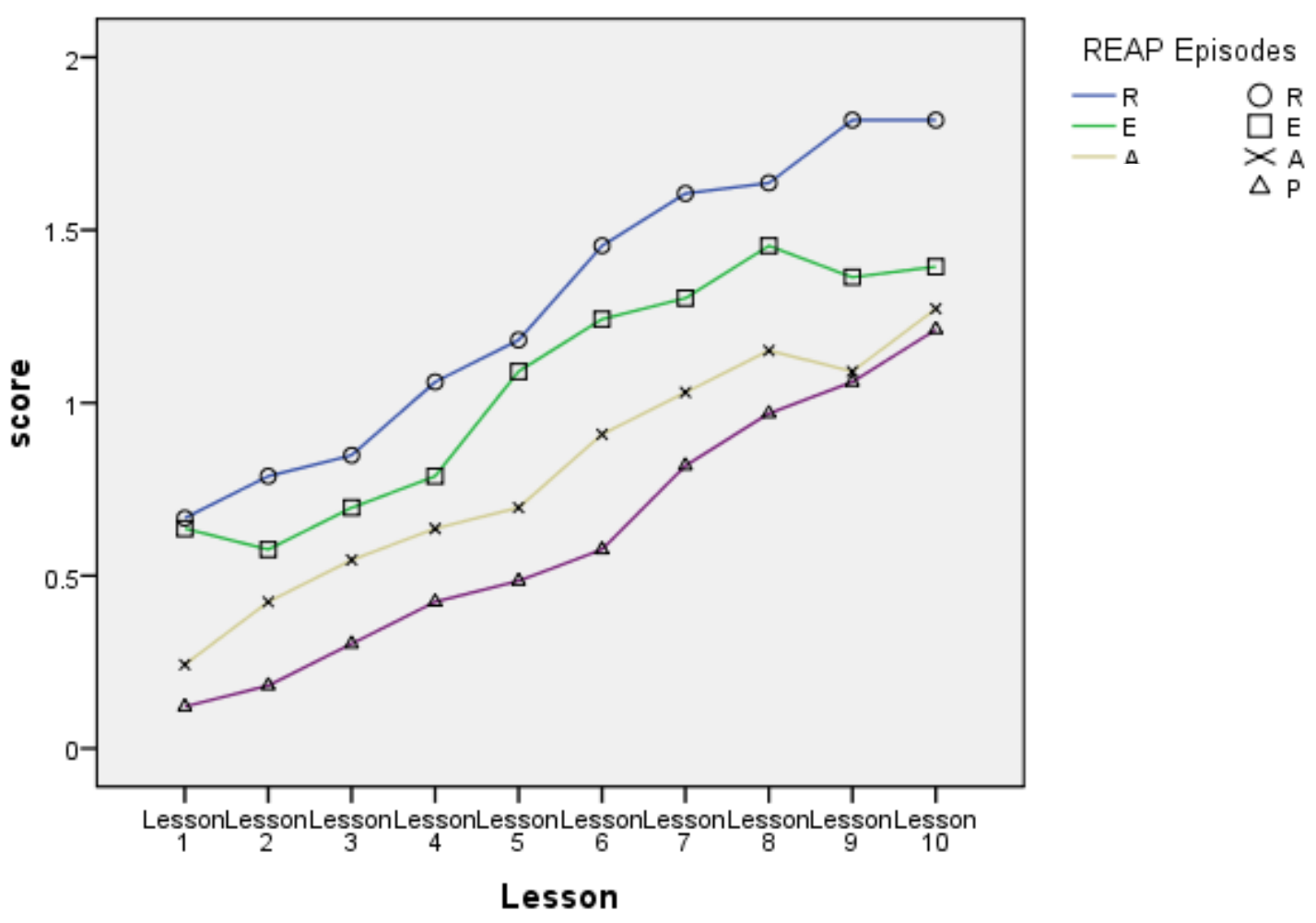

Figure 6. Mean score for each REAP episode on the worksheet

Moreover, classroom observation of the REAP lessons confirmed that students were highly enthusiastic during most of the REAP lessons. Some students were observed confused at the beginning of the REAP lessons, maybe because the REAP reading strategy was new. However, after the first 3 lessons, students started utilizing the strategy while reading the texts. Particularly at the beginning of the intervention, the teacher was highly involved in helping the students apply the strategy and provided guidance to some students when they needed. Around the end of the intervention, many of the students were observed actively engaged while reading the texts and activities like marking the texts, writing notes on the text margin, and exchanging ideas each other about the information they read were observed.

\section{Discussion}

The aim of this study was to examine the effectiveness of REAP strategy instruction in improving the reading comprehension of grade 8 students in an upper primary school in Ethiopia. Two intact sections were identified and assigned randomly into an experimental and a control condition. The experimental class was taught to employ REAP reading strategy for 10 lessons and their progresses during each lesson was evaluated using a REAP worksheet. On the other hand, the control group was taught through the regular method of teaching reading for 10 reading lessons, and their reading comprehension progress in each lesson was measured using an open-ended item worksheet. Pre-test and post-tests were administered to 
evaluate the effectiveness of the REAP reading strategy.

Analyses of pre-test performance indicated that there was no significant difference in reading comprehension between students in the control and experimental conditions. However, after 4 weeks of intervention of 10 REAP lessons for the experimental condition, and 10 regular reading lessons for the control condition, significant difference was found. The result indicated that students in the experimental condition outperformed those in the control condition. Analyses of students' responses to the worksheets during each lesson also indicated that students in the experimental condition demonstrated consistent improvement in their reading comprehension than those in the control condition.

Repeated classroom observations during the actual lessons provided some evidence about the possible reasons for the differences in students' reading comprehension achievement. The REAP strategy instruction created an environment for students to be highly engaged in the reading activities and work in collaboration. At the beginning of the experimental sessions, there was little confusion among students on how to deal with REAP. It was a new learning experience for them. However, after repeated teacher modeling of the strategy and explicit instruction, students were observed participating actively on the reading tasks. The REAP worksheets helped students to be on-task during each lessons. The moment the teacher handed the reading text with the REAP worksheet attached, the students immediately started working on the text. Compared to the beginning of the intervention, the teacher's involvement around the end of the intervention reduced considerably. Students were observed actively involved in the reading activities: underlining and highlighting key words, writing notes on text margins, attempting to write a summary of the text, reading and giving comments on other student's summary, and discussing among dyads on how the new information they read is related with what they already know. These were indications that students were actively engaged during the reading lessons. Previous research has shown that when teachers create learning environments that enable reading engagement to be extensive and satisfying, students' reading comprehension and their measurable achievement increases (Guthrie \& Cox, 2001; Guthrie, 2004).

On the other hand, repeated classroom observations of the control condition revealed that students were less engaged and had demonstrated limited collaboration. The students were not observed employing a particular strategy during the reading activities. Sometimes, the teacher asked a student to read aloud a text to the whole class and others were listening. In other occasions, the teacher himself read aloud the texts. Immediately, the students were requested to answer the open-ended comprehension items. Some of the students spent much of instructional time in re-reading the texts, and by the end of the lessons they were able to complete only half of the questions on the comprehension worksheets. Moreover, the strategy the teacher employed did not help students to collaborate during the reading tasks and the teacher appeared to have a dominant role during the lessons. 


\section{Conclusion}

This study reveals that explicit reading strategy instruction (REAP) to upper primary school students significantly improved their reading comprehension. This finding is consistent with previous studies, which indicated that the use of REAP strategy instruction has resulted in a higher reading comprehension of students (Eanet \& Manzo, 1976; Tasdemir, 2010).

Although the result has shown the effectiveness of REAP in improving the reading comprehension of students, there were limitations to this study. The study clearly showed that primary school students' reading comprehension could be improved through explicit reading strategy instruction. However, firstly, the sample size of this study was very limited: only one teacher and two intact grade 8 classes were involved. Besides, the REAP intervention lasted only for 10 lessons. Hence, future research with extended intervention period and a larger sample size is recommended. Secondly, due to financial and time constraints, it was impossible to include additional data gathering instruments such as teacher and student interviews. Future research may need to include diverse data gathering instruments including interviews on teacher and students' opinions about the REAP reading strategy.

\section{References}

Aarnoutse, C., \& Van Leeuwe, J. (2000). Development of Poor and Better Readers During the Elementary School. Educational Research and Evaluation, 6(3), 251-278. http://dx.doi.org/10.1076/1380-3611(200009)6:3;1-A;FT251

Alvermann, D., \& Earle, J. (2003). Comprehension instruction. In A. P. Sweet \& C. Snow (Eds.), Rethinking reading comprehension (pp. 12-30). New York: Guilford Press.

Anderson, R.C., \& Pearson, P.D. (1984). A schema- theoretic view of basic processes in reading comprehension. In Pearson, P.D. (Ed.), Handbook of reading research (255-291). New York: Longman.

Cohen, L. Manion, L., \& Morrison, K. (2007). Research Methods in Education. London: Routledge.

Cunningham, A.E., \& Stanovich, K.E. (1997). Early reading acquisition and its relation to reading experience and ability 10 years later. Developmental Psychology, 33(6), 934-945. http://dx.doi.org/10.1037/0012-1649.33.6.934.

De Corte, E. Verschaffel, L., \& De Ven, A. (2001). Improving text comprehension strategies in upper primary school children: A design experiment. British Journal of Educational Psychology, 71, 531-559. http://dx.doi.org/10.1348/000709901158668.

Duke, N.K., \& Pearson, P.D. (2002). Effective practices for developing reading comprehension. In A.E.Farstup \& S.J. Samuels (Eds.), What research has to say about reading instruction (pp. 205-242). Newark, DE: International Reading Association.

Eanet, M.G., \& Manzo, A.V. (1976). REAP - A Strategy for Improving 
Reading/Writing/Study Skills. Journal of Reading, 19(8), 647-652.

Errington, E. (2004). The impact of teacher beliefs on flexible learning innovation: some practices and possibilities for academic developers. Innovations in Education and Teaching International, 41(1), 39-47. http://dx.doi.org/10.1080/1470329032000172702.

Guthrie, J. (2004). Teaching for Literacy Engagement. Journal of Literacy Research, 36(1), 1-29. http://dx.doi.org/10.1207/s15548430jlr3601_2

Guthrie, J. T., \& Cox, K. E. (2001). Classroom Conditions for Motivation and Engagement in Reading. Educational Psychology Review, 13(3), 283-302. http://dx.doi.org/10.1023/A:1016627907001

MoE (Ministry of Education). (2010). Education Sector Development Program: ESDP IV (2010/2011-2014/2015). Addis Ababa: Ministry of Education.

MoE (Ministry of Education). (2008). Ethiopian Third National Learning Assessment. Addis Ababa: Ministry of Education.

NOE (National Organization for Examinations). (2004). Ethiopian Second National Learning Assessment of Grades 4 \& 8 Students. Addis Ababa: NOE/MOE.

NOE (National Organization for Examinations). (2000). Ethiopian Baseline National Learning Assessment of Grades 4 \& 8 Students. Addis Ababa: NOE/MOE.

OECD (2009). PISA 2009 Assessment Framework - Key Competencies in Reading, Mathematics and Science. OECD, Paris.

Palincsar, A.S., \& Brown, A.L. (1984). Reciprocal Teaching of Comprehension-Fostering and Comprehension-Monitoring Activities. Cognition and Instruction, 1(2), 117-175. http://dx.doi.org/10.1207/s1532690xci0102_1

Pressley, M., El-Dinary, P., Gaskins, I., Schuder, T., Bergman, J., Almasi, J., \& Brown, R. (1992). Beyond Direct Explanation: Transactional Instruciton of Reading Comprehension Strategies. The Elementary School Journal, 92(5), 513-555.

Pressley, M., \& Wharton-McDonald, R. (1997). Skilled comprehension and its development through instruction. School Psychology Review, 26(3), 448-467.

Pressley, M. (1998). Reading Instruction That Works: The Case for Balanced Teaching. New York: The Guilford Press.

Pressley, M. (2000). What should comprehension instruction be the instruction of? In M.L. Kamil, P.B. Mosenthal, P.D. Pearson, \& R. Barr (Eds.), Handbook of reading research: Volume III (pp. 545-561). Mahwah NJ: Erlbaum.

Rosenshine, B, \& Meister, C. (1994). Reciprocal teaching: A review of nineteen experimental studies. Review of Educational Research, 64, 479-530.

Rosenshine, B., Meister, C., \& Chapman, S. (1996). Teaching students to generate questions: A review of the intervention studies. Review of Educational Research, 66, 181-221. 
Simpson, M.L., \& Nist, S.L. (1990). An Effective and Efficient Study Strategy for College Students. Journal of Reading, 34(2), 122-129.

Smith, M.C., Mikulecky, L., Kibby, M.W., \& Dreher, M.J. (2000). What will be the demands of literacy in the workplace in the next millennium? Reading Research Quarterly, 35(3), 378-383.

Tasdemir, M. (2010). The effects of the REAP reading comprehension technique on students' success. Social Behavior and Personality, 38(4), 553-560.

USAID (2010). Ethiopia Early Grade Reading Assessment: Data Analytic Report Language \& Early Learning. RTI International and the Center for Development Consulting.

Van Keer, H. (2004). Fostering reading comprehension in fifth grade by explicit instruction in reading strategies and peer tutoring. British Journal of Educational Psychology, 74, 37-70. http://dx.doi.org/10.1348/000709904322848815.

Williams, J.P. (2005). Instruction in Reading Comprehension for Primary-Grade Students: A Focus on Text Structure. The Journal of Special Education, 39(5), 6-18. http://dx.doi.org/10.1177/00224669050390010201.

Zywica, J., \& Gomez, K. (2008). Annotating to Support Learning in the Content Areas: Teaching and Learning Science. Journal of Adolescent \& Adult Literacy, 52(2), 155-165. http://dx.doi.org/10.1598/JAAL.52.2.6

\section{Appendix}

\section{Appendix 1. Sample reading text}

\section{The National Museum}

The Ethiopian National Museum is one of the leading Museum institutions in Ethiopia. It is the oldest, the largest and the richest in its collection throughout Sub-Saharan Africa. It was founded in 1936 and is located in Addis Ababa, the capital city of Ethiopia. At present, the National Museum displays numerous artifacts mainly from archaeology. Some of the artifacts are from the earliest days in Ethiopia such as the pre-Axumite civilization of Abyssinia.

The building of the National Museum has at present four main exhibition sections.

The basement contains various fossils, the most famous of which are the remains of Lucy. Lucy is the nickname given to a 3.5 million year old female skeleton that is fossilized. Lucy is also named Dinknesh in Amharic. She was found in 1974 in the Afar Depression. Much of her jaw is missing, but the remaining jaw contains almost all of its teeth. Scientists say that Lucy is the earliest known hominid skeleton. Hominids were the apes that learned to walk on two legs.

The first floor contains artifacts from all parts of Ethiopia such as sculptures, ceremonial clothing, thrones and tables. The second floor is devoted to traditional and contemporary Ethiopian art work. The paintings have scenes from markets, religion, and other activities. There are woodcuts, 
self-portraits, and many other types of paintings. On the third floor, visitors have good opportunity to see the mosaic of ethnographic records of the country. Here, the Museum tries to give an overview of the cultural richness and variety of the people of Ethiopia.

Many people from all over the world visit the Ethiopian National Museum. A tour guide is available to walk with you and explain the many exhibits in the entire museum. It is open 7 days a week, from 8.30 to 17.30 .

\section{Appendix 2. Mean and Standard deviation of REAP lessons}

Table 1. Means and Standard Deviations of Experimental Class REAP Lessons

\begin{tabular}{|c|c|c|c|c|c|c|c|c|c|}
\hline \multirow{3}{*}{ Lessons } & \multicolumn{8}{|c|}{ REAP score } & \\
\hline & \multicolumn{2}{|l|}{$\mathrm{R}$} & \multicolumn{2}{|l|}{$\mathrm{E}$} & \multicolumn{2}{|l|}{ A } & \multicolumn{2}{|l|}{$\mathrm{P}$} & REAP \\
\hline & Mean & St. Dev. & Mean & St. Dev. & Mean & St. Dev. & Mean & St. Dev. & $\begin{array}{l}\text { Total Mean } \\
\text { (St. Dev.) }\end{array}$ \\
\hline Lesson 1 & .67 & .54 & .64 & .55 & .24 & .44 & .12 & .33 & $1.67(0.96)$ \\
\hline Lesson 2 & .79 & .42 & .58 & .50 & .42 & .50 & .18 & .39 & $1.97(1.02)$ \\
\hline Lesson 3 & .85 & .44 & .70 & .59 & .55 & .51 & .30 & .47 & $2.39(1.06)$ \\
\hline Lesson 4 & 1.06 & .43 & .79 & .55 & .64 & .55 & .42 & .56 & $2.91(1.40)$ \\
\hline Lesson 5 & 1.18 & .53 & 1.09 & .58 & .70 & .47 & .48 & .57 & $3.45(1.42)$ \\
\hline Lesson 6 & 1.45 & .56 & 1.24 & .44 & .91 & .46 & .58 & .61 & $4.18(1.33)$ \\
\hline Lesson 7 & 1.61 & .50 & 1.30 & .48 & 1.03 & .48 & .82 & .47 & $4.76(1.09)$ \\
\hline Lesson 8 & 1.64 & .55 & 1.45 & .62 & 1.20 & .44 & .97 & .47 & $5.21(1.27)$ \\
\hline Lesson 9 & 1.09 & .46 & 1.36 & .55 & 1.09 & .46 & 1.06 & .50 & $5.33(1.14)$ \\
\hline Lesson 10 & 1.82 & .34 & 1.39 & .56 & 1.27 & .63 & 1.21 & .60 & $5.70(1.33)$ \\
\hline
\end{tabular}

\section{Copyright Disclaimer}

Copyright reserved by the author(s).

This article is an open-access article distributed under the terms and conditions of the Creative Commons Attribution license (http://creativecommons.org/licenses/by/3.0/). 